\title{
1. Introduction: Thinking about Italian mafias today
}

\section{Felia Allum, Isabella Clough Marinaro and Rocco Sciarrone}

Still today Italian mafias are widely dismissed as 'an Italian problem' despite vast evidence that these criminal groups have expanded well beyond Italy as their base for business. All of Italy's mafia groups have become - in fact many have long been - transnational in their economic and political activities and in their social effects. While the very real damage that these groups wreak on democratic processes, on fair market competition, on the environment and on the livelihoods and wellbeing of communities in Italy and abroad is often ignored, popular culture has ensured that they have become part of our global collective imagination.

Recent films and TV series such as Gomorrah, the US 'reality' TV show Mob Wives and the novel The Piranhas (Roberto Saviano, 2018) continue to fuel our images of mafiosi's exciting and fearless lifestyles, their appetite for violence, their endless exuberance and kitsch glamour, appearing to embody the dark side of contemporary capitalist society. While no doubt enjoyable, these fictional representations cloud a reality that is far less exotic and yet much more complex.

This book aims to provide an accurate, extensive and updated picture of how Italian mafias operate today: ${ }^{1}$ how they organise, how they behave and how they adapt to changing economic opportunities and intensified attention from law enforcement and civil society. There is a long tradition of books in English that trace the development of Italian mafias especially in the run-up to the great moment of crisis of 1992-94, when the Sicilian Cosa Nostra embarked on a terror campaign against the Italian state, when the political system collapsed under the weight of corruption scandals, when a new set of actors and strategies for dealing with mafias began to emerge. Very few books, however, have tried to unravel the dramatic changes that have occurred in the quarter-century since then, and when they have, they have been partial - with a focus on a single criminal phenomenon - or primarily descriptive. This book breaks with the tradition of historical narratives on the mafias and proposes 
instead a set of theoretical and analytical frameworks to understand the transformations of recent decades. The case studies presented cut across the four major Italian mafias, analysing their internal mechanisms and strategies of survival and development, their relationships with collusive actors in business and politics, the challenges and opportunities they have met when trying to expand beyond their territories of origin. Collectively, the chapters propose a novel set of theoretical lenses and innovative methodologies for analysing these developments, interlaced with historical detail to provide necessary context. Written by a group of international experts - some of them leading national policy consultants - this book brings interdisciplinary attention to some of the least studied and emerging aspects of contemporary organised crime.

The main objective of this book is to provide a broad - albeit not exhaustive - overview of a number of themes and research findings that have been developed in recent years by Italian social scientists focusing on Italian mafias. This is a body of work that is often little known to scholars outside Italy's national context, and which in turn engages all too infrequently with the international organised crime literature. The reasons for this limited integration between different national and European research communities are too numerous to be developed here ${ }^{2}$ but it is important to underline that scholars who concentrate on analysing Italian mafias view them as a unique form of organised crime: an ideal type category of criminal association. While it is an undoubtedly criminal phenomenon, it is not entirely comparable to more widespread forms of organised crime. Indeed, what most characterises the mafia phenomenon are the complex and multiform relational networks that these groups entwine with political, institutional and economic spheres. Thus, they exhibit a particular combination of territorial control and profit-making activities. In this sense, as we will see in the volume's individual chapters, mafias can be considered an entirely distinctive model of organised crime, able to exert forms of regulation and extra-legal governance on social, political and economic life. As scholarly studies on Italian mafias have become increasingly rich and variegated, a discernible theoretical field and set of research approaches is now becoming consolidated. In the following paragraphs we provide a brief overview of the evolution of mafia studies in the Italian social sciences, highlighting core phases of development, analytical perspectives and emerging themes.

Following a flurry of attention to the topic - especially regarding the Sicilian mafia and Neapolitan Camorra - in the decades straddling the late nineteenth and early twentieth centuries, Italian social scientists showed fluctuating interest in studying the phenomenon. Even in the decades after World War II the problem was addressed only in a sporadic and haphazard way. Media coverage of criminal events and police investigations cyclically attracted public interest and the issue was even debated at the political level. Indeed, in 1962 a law was passed that instituted the first Parliamentary Anti-mafia Committee, a bicam- 
eral investigative body made up of 25 deputies and 25 senators, mandated to enquire into the phenomenon and propose legislation and tools to fight it. ${ }^{3}$ It is paradoxical, therefore, that until the end of the 1970s the most important scientific studies were carried out by foreign scholars (Hess 1973; Blok 1974; Schneider and Schneider 1976). ${ }^{4}$ In his work, Anton Blok (1974, chapter 1) attributed this paucity of attention to the limited development of the social sciences in Italy, which he claimed was reflected in a deficiency of research methods and tools. This harsh diagnosis was not entirely correct, though. Italian social scientific research was very active in those years on many complex fronts; however, mafias were not considered a relevant issue for scholarly investigation, nor particularly useful for analysing conditions in southern Italy. At the time, in fact, mafias were mainly considered an expression of economic and cultural backwardness of southern regions; a consequence of ancient production methods and a remnant of traditional mindsets (Lupo 2009). Attention therefore focused on developing the south, on industrialising it and introducing modernisation processes more generally which, it was argued, would sweep away archaic structures and the mafias that rested on them. This perspective influenced interpretative approaches for a long time, resulting in mafias being considered essentially a manifestation of Sicilian or southern sub-cultures. The phenomenon was thus conflated with its area of origin; the former seen as a direct emanation of the values and cultural codes of the latter. Upon these foundations the 'culturalist' paradigm took shape and crystallised over time, causing the mafias to be understood as a question of mentality specific to various parts of the south (Sciarrone 2009). This argument also long justified the idea that they were therefore unable to move outside their original regions. Their spheres of activity and their very existence were assumed to be tightly bound to the local conditions and contexts of their birth, while other areas, such as the north of Italy, were simultaneously considered impermeable to mafia infiltrations due to their higher levels of modernisation and economic development. Among its many inherent weaknesses, this understanding of the mafia obstructed an analysis of its organisational aspects (Catino 2014a), resulting in a failure to evaluate it on a par with other forms of organised crime, limiting it conceptually to a group of 'men of honour' connected through primary bonds and shared cultural codes such as omertà (the code of silence).

This picture changed at the start of the 1980 s as violence escalated dramatically in Sicily, targeting leading political, judicial and law enforcement figures. At the same time, brutal 'mafia wars' were causing hundreds of deaths among criminal groups not only in Sicily but also in Campania and Calabria. In an attempt to tackle this situation, the Rognoni-La Torre was passed in 1982, introducing the crime of mafia-type association into the Penal Code, ${ }^{5}$ in the following years legislation was also passed to encourage and regulate the collaboration between mafiosi and the judicial authorities. These 
developments opened the way for the momentous 'maxi-trial' which began in Palermo in 1986, in which hundreds of mafia bosses and affiliates were found guilty and Cosa Nostra was recognised as a unitary and hierarchical criminal organisation. As is well known, this period culminated in the massacres of 1992 in which the magistrates Giovanni Falcone, Francesca Morvillo, Paolo Borsellino and the members of their police escort were murdered, followed by a series of terrorist-style bombings in 1993 which targeted monuments and symbolic locations in Rome, Florence and Milan.

This historic moment generated a strong impetus for scientific research on the mafias: on the one hand, as often happens, growing public attention stimulated academic interest in the phenomenon; on the other, the new information available (for example, the testimonies of mafiosi turned state's witnesses) opened up novel avenues for analysis. ${ }^{6}$ In those years important historical and sociological studies came out and the 'culturalist' paradigm began to be countered by an 'organisationalist' one which highlighted mafias' structured and corporate character as criminal groups. Historians identified this as a long-lasting feature of many Cosa Nostra clans, emphasising continuities in the families involved, their hierarchies and leadership over time. ${ }^{7}$ From a sociological perspective, mafias were analysed as businesses and their members as entrepreneurs: Pino Arlacchi (1986) advanced the concept of 'enterprise mafia', Raimondo Catanzaro (1992) defined mafiosi as 'entrepreneurs of violence' and Diego Gambetta (1992) saw the mafia as a 'business of private protection'.

With this shift in emphasis away from mafias' cultural and contextual specificities, the analytical perspectives started to draw from the broader theoretical field of organised crime, examining similarities and differences to other groups, or considering them a specific subset of larger phenomena. Economic methodologies - or studies that underlined the importance of mafias' economic features and their entrepreneurial strategies across legal and illegal markets - became widespread. Nevertheless, the most discerning authors emphasised that mafias are a very specific and unique form of organised crime which merge together economic and political goals. Indeed, while mafias have always pursued wealth, they also demand to exert power over specific territories, social circles and business sectors. ${ }^{8}$ It is therefore necessary to understand how this power is legitimised and how mafiosi are able to enjoy a certain level of social approval. From this perspective, analysing the cultural dimension has become important again, together with grasping other contextual factors that can produce more or less favourable structural environments for clans to operate and reproduce themselves across time and space. Indeed, it is no coincidence that in recent years there has been a great increase in attention to the processes of territorial expansion of mafias away from their areas of origin into non-traditional ones in northern Italy and abroad. ${ }^{9}$ At the same 
time, promising developments are emerging in studies using network analysis (Calderoni 2018), as well as various lines of research that examine the symbolic dimensions of mafias and their membership ties, for example focusing on the important role of women within them (Siebert 1996; Fiandaca 2007).

Then, with the publication of Roberto Saviano's (2007) blockbuster novel Gomorrah, the collective imagination concerning mafias changed radically, contributing to the spread of new social representations that have fuelled public debate and encouraged a substantial rise in publishing on the subject ever since. Not only has the number of Italian books on mafias grown, but so have films, TV series and documentaries. All of these literary and media representations further contribute to the social construction of mafias; that is, perceptions of their distinctive traits, the threats they pose and how they should be fought. Indeed, an important research thread that has developed in recent years focuses specifically on the policies and practices that have been implemented to try to defeat the mafias on the part of social movements and associations and by political institutions and law enforcement agencies (La Spina 2016a). The awareness has thus spread that in order to study the mafias, the anti-mafia fight must also be investigated since the two take shape together and are tightly intertwined.

Consequently, a view is now becoming consolidated that the most effective approach to understanding this phenomenon is to adopt multidimensional and process-based lenses (Santino 2006). This requires taking into account, on the one hand, the various features - and the relationships and interdependencies between these - that distinguish the mafias; on the other hand, it requires identifying elements of continuity and discontinuity, mafias' immense ability to adapt to economic and social change and the very different types of mafias that exist, sharing some common aspects but also many divergent ones. From this point of view, the Sicilian mafia, Cosa Nostra, has undoubtedly been the most studied (Paoli 2003; Dickie 2004; Lupo 2009; Dino 2009, 2016). Recent years have also seen the expansion of research on various Camorra groups (Allum 2006; Brancaccio and Castellano 2015), while there are still relatively few investigations specifically dedicated to the Calabrian 'Ndrangheta, despite the fact that it is now the most dangerous mafia domestically and internationally (Paoli 2003; Serenata 2014; Sergi and Lavorgna 2016). In parallel to this attention to traditional mafias, there has been a rise in interest concerning 'new' or emerging ones, such as the Sacra Corona Unita which developed in Puglia between the 1970s and 1980s, or the more recent case of Mafia Capitale: a criminal grouping active in Rome which in many ways adopted mafia methods while originating, and being specifically anchored, in the context of the capital, with no roots in the historic mafias.

Lastly, Italian scholarship is now also paying close attention to two interlinked issues: 1) the growing presence of mafias in the legal economies of their 
traditional areas and those of more recent expansion, within which collusive exchanges and deals are made with entrepreneurs, professionals and other economic actors $;{ }^{10} 2$ ) the interactions between mafias and white-collar criminals and with corrupt political-administrative apparatuses. ${ }^{11}$ It is becoming clear that, in addition to using their traditional intimidatory power, mafiosi are increasingly availing themselves of corruptive-collusive methods in order to consolidate their power and enhance their ability to do business.

This volume investigates and expands on some of these emerging themes. It compensates for the so far scarce emphasis that has been given to the role of enablers and facilitators - known in Italian as the 'grey area/zone'; the entrepreneurs, politicians, lawyers, accountants, bank clerks, public administrators, doctors and other professionals who are not affiliated mafia members but whose active or passive support is crucial to their survival and success.

Another central theme that we engage with extensively is the ability of mafias to combine traditional values with continuous adaptability to external change, running efficient business activities with strict internal rules and values that enable them to demand total respect, control the daily lives of their members and thereby persist through time. In parallel to the deep-rooted values of violence and omertà, mafias have built their own 'welfare systems' to look after their members in times of need, creating a mechanism of trust based on financial security and support.

Another manifestation of this bridging of traditional values and loyalties with forward-looking entrepreneurial strategies is various mafias' proven ability to not only survive but also become socially and politically embedded in new environments. This means that they are no longer an Italian problem but a global one. In this volume, we compare why and how they move, in the hope of identifying patterns that can be useful for predicting and averting future expansions. The various chapters therefore offer a toolkit for understanding the most recent transformations within Italian mafias and especially for analysing how they develop temporally and spatially. We thus observe them in action in their traditional and new locales, focusing both on their adaptation to external forces and their strategies of action vis-à-vis politics and the legal economy.

While this book covers a wide range of interlinked themes, there are a number of important ones that are not as deeply explored as they deserve to be and which future publications will need to address in more detail. The first is the role of women, without whom the Italian mafias could not survive. They form the backbone of these organisations, despite their profoundly patriarchal and misogynistic ideologies. The often invisible participation of mothers, sisters and wives can be considered key to their long-term functioning and strength. Women take the place of men who are imprisoned or killed, but as yet not one woman has made it to the top without being related to a leading mafioso. This may change, however, as women prove themselves to be very capable, 
multitasking criminals. A second topic, and one that is currently fashionable in organised crime studies, concerns emerging relationships and commonalities between organised crime and terrorist groups, the so-called 'crime-terror nexus'. So far, there is little evidence to suggest that Italian mafias actively seek to enter into pacts with ideological terrorist groups. Rather, they may come into contact and engage in a functional exchange of tools or goods, but Italian mafias are not becoming terrorist groups, as has happened in some other parts of the world, and terrorist groups are not becoming mafias, despite the anomalous terrorist-style behaviour of Cosa Nostra in the 1990s.

Third, technological innovation is rapidly changing criminal markets through the proliferation of cybercrimes and the expansion of the dark net. While Italian mafias are adapting to these developments by using tools that better hide their communications from law enforcement agencies, and using social media to share images in order to underline their power, family ties and wealth, there is as yet little evidence that they are radically changing their business models by turning to new forms of e-technology to undertake crimes. Italian mafias need physical territory to exist; taking on virtual identities would weaken the many activities that are based on their geographical presence. While they may use Facebook as 'a virtual piazza' to insult rivals, start very real fights and send messages to followers, this has not yet translated into new criminal enterprises, but given their versatility, this may well change in the future.

This volume is organised into three interlinked parts. Part I, 'Mafias in Traditional Territories', examines how Italy's four main mafias have evolved in recent decades, responding to developments in legislation, policy and law enforcement strategies, and to changing relations with social actors in their regions of origin. Alessandra Dino (Chapter 2) provides an overview of the development of Cosa Nostra since its brutal second war and the massacres of 1992-94. She highlights its internal renegotiations of power in the period following those upheavals and the current serious leadership crisis that is making its future prospects very uncertain. In Chapter 3, Brancaccio and Martone focus on the entrepreneurial nature of Camorra clans operating in the city of Naples and in the provinces, demonstrating how their power is rooted in local markets, both legal and illegal, such as counterfeits, clothing and the international car trade. In Chapter 4, Ciconte traces how extensive institutional denial about the 'Ndrangheta's power, alongside its own strategy of invisibility, have enabled it to evolve into one of Italy's most wealthy, dangerous, expansive and efficient mafias today. Massari (Chapter 5) then outlines the history, characteristics, strategies and most recent evolution of the Sacra Corona Unita, a relatively new mafia-type organisation, born in the 1970s/1980s in Apulia. The author explains the internal weaknesses which have made it vulnerable to law enforcement operations, while arguing that a second generation is 
emerging to counter the frequent assumption that the organisation is now defunct. Together, these four chapters also reveal how developments within one mafia or region has knock-on effects on others, creating new opportunities and challenges.

Part II, 'Mafias between Politics, Economy and Society', provides in-depth analyses of some of the central strategies and practical dimensions of mafia behaviour which enable these organisations to sustain their strength and ensure their survival in an increasingly hostile and complex social environment. Sciarrone, in Chapter 6, investigates the dynamics at play in Italy's extensive 'grey area' of professional figures who facilitate mafia activity and profit from it economically, interpenetrating with the organisations while not formally affiliating with them. He highlights how the mafias draw these actors into collusion and complicity, using them to build the social capital that is key to their success. In Chapter 7, Sberna and Vannucci unpack the mutual benefits for mafiosi and politicians in building corrupt relationships and the diverse balances of power that they negotiate between themselves. The authors provide a theoretical framework to capture the variation in these relationships geographically and over time, then assess some of the most recent developments in Italy's political-criminal nexus. The following two contributions explore internal strategies mobilised by two mafias to strengthen identity and loyalty among their members: in Chapter 8, Colletti analyses the welfare system which many Italian mafias have put into place, weaving together economic ties and incentives to build in-group cohesion and consensus. It focuses on the function of the common fund in financing this form of assistance and examines the main types of protection provided. In Chapter 9, Merlino explores the changing discursive methods used within Cosa Nostra to reinforce shared cultural frameworks among members in its recent period of intense crisis. It focuses particularly on the written system of communication (pizzini) implemented under the leadership of Bernardo Provenzano, arguing that those communications had an influential effect on the organisation's identity and structure.

Part III, 'Mafias in Non-Traditional Territories', contributes to growing debates on how organised crime groups expand, the opportunities and challenges that influence those expansions and the resources that they exploit in doing so. ${ }^{12}$ A composite picture emerges from the individual case studies, demonstrating both the diverse abilities and interests of criminal groups - even from within the same overarching organisation - to develop activities and put down roots in new locations. In Chapter 10, dalla Chiesa examines the expansion and presence of the 'Ndrangheta in the rich northern region of Lombardy, arguing that a process of colonisation is under way, carried out through silent conquest from below and the effective use of low-profile violence. It demonstrates how the organisation conditions local political and economic life in the region while simultaneously maintaining close ties with Calabria. Corica 
and Mete (Chapter 11) then investigate the strategies whereby mafias have infiltrated another, less explored, northern region, Emilia Romagna, focusing particularly on a branch of the 'Ndrangheta that has been active there for over 40 years. In Chapter 12, Clough Marinaro and Giuditta Borselli analyse the trajectories of three Camorra clans in their attempts to expand into the Italian capital, showing the diversified strategies and variable levels of success that have been achieved. In comparing their resources and economic and geographical sectors of interest, the study offers some preliminary conclusions about Rome's vulnerabilities as a 'new' destination of mafia expansion. In Chapter 13, Dagnes, Donatiello and Storti map how Italian mafias - especially the 'Ndrangheta - have been able to expand internationally, into several other European countries. Their study demonstrates that mafias' presence abroad is neither unique nor stable over time, and focuses on four dimensions that underline the complexities and evolutions: 1) mafias' economic activities (illegal and legal); 2) their organisational structure in international contexts; 3) the degree of embeddedness and cooperation achieved with politicians, entrepreneurs and other actors abroad; and 4) the relationship with the home territory. Allum and Bright in Chapter 14 present an overview of the presence of Italian mafias in Australia and compare the very different social and economic behaviours of the 'Ndrangheta and the Camorra there. The authors consider the interplay of multiple factors which have resulted in the 'Ndrangheta becoming a territorially and politically rooted mafia, while Camorra groups use Australia as a 'marketplace' in which to generate profit rather than for long-term settlement. In the final chapter, La Spina then provides an overview of how anti-mafia policy has evolved in Italy in the last decades, becoming ever more holistic and effective, and how the country's particular experiences have influenced European Union policy debates, while also helping to shed light on the United States' evolving approach to organised crime nationally and globally.

\section{NOTES}

1. We use the term mafia or mafias to refer generically to a phenomenon which has multiple expressions over time and space. When focusing on a specific mafia, we adopt its commonly used name: Cosa Nostra for the main Sicilian group, 'Ndrangheta for the Calabrian form, Camorra for the Campanian groups and Sacra Corona Unita for the phenomenon in Apulia.

2. See for example Varese (2010) on this issue.

3. The committee has been instituted in every subsequent parliamentary term apart from the seventh (July 1976-June 1979).

4. In roughly the same years, a series of studies taking a different approach focused on the Italian mafia in the United States (see for example Cressey 1969; Albini 1971; Ianni and Reuss-Ianni 1972; Smith 1975; Anderson 1979; Block 1980). Earlier analyses were also carried out by special committees chaired by Senator E. Kefauver in 1950-51 and by Senator J. McLellan in 1957-60, followed by 
a President's Commission on Law Enforcement and Administration of Justice in 1965-67. See Lupo 2015 on these inquiries and the debates they generated.

5. Before the introduction of this law, mafia crimes were punished under article 416 of the Penal Code (criminal association), but this was often ineffective in dealing with the specificities of mafia-type crime. Article 416 bis was therefore introduced into the Penal Code in 1982 to define mafia-type association in cases where participants use intimidation to carry out economic activities, acquire advantages for themselves or others and influence elections. In cases of such crimes, the state can confiscate the illegally acquired assets of the accused. In 1996 a law was introduced that allows for the reuse of confiscated assets for projects of social value by assigning them to local institutions, cooperatives and associations.

6. See Arlacchi 1992; Dino 2016.

7. Pezzino 1990; Dickie 2004, 2012; Santino 2006; Lupo 2009; Benigno 2015; Sales 2015.

8. See for example Sciarrone 2006; Catanzaro and Santoro 2009; Dino 2009, 2011a; Santoro 2015; Massari and Martone 2019.

9. See Sciarrone 2009, 2014a; Varese 2011; Allum 2014, 2016; Sciarrone and Storti 2014; Sergi 2015a; Calderoni et al. 2016; dalla Chiesa 2016; Sergi and Lavorgna 2016; Martone 2017; Belloni and Vesco 2018.

10. See for example, Lavezzi 2008, 2014; Sciarrone 2010, 2011, 2014a; Savona and Riccardi 2015; Sciarrone and Storti 2016; Savona et al. 2017.

11. See for example, Allum 2010; della Porta and Vannucci 2012; Ruggiero 2015; Sciarrone 2017.

12. For reasons of space we have not been able to include a chapter on Italian mafias in the Americas, especially the United States and Canada. As note 4 partly indicates, the United States has already been widely studied. In particular we refer readers to the seminal historical text by Salvatore Lupo (2015). On the Canadian situation, see Sergi (2018). 